\title{
Clustering of Muscle Acetylcholine Receptors Requires Motoneurons in Live Embryos, but Not in Cell Culture
}

\author{
Dennis W. C. Liua and Monte Westerfield \\ Institute of Neuroscience, University of Oregon, Eugene, Oregon 97403
}

\begin{abstract}
Previous culture studies have demonstrated that muscle cells autonomously express and cluster ACh receptors (AChRs) and that contact by neurites induces a reorganization of these clusters. We studied these phenomena in zebrafish embryos where the same cells could be examined in vivo and in vitro, and where contacts between cells could be viewed repeatedly. Receptor clusters first appeared when the pioneer growth cones emerged from the spinal cord, were always associated with labeled branches, and developed normally in the presence of neuromuscular transmission blockers. When motoneurons were removed, the muscles failed to cluster receptors. In contrast, muscle cells grown in cell culture uncontacted by nerves clustered AChRs. Our results suggest that clustering of AChRs in living embryos is induced by the presence of neurites and does not occur in the absence of neuronal contact. We suggest that conditions in cell culture, which differ from those in the intact embryo, induce clusters on isolated muscle cells. Moreover, our results demonstrate that receptors cluster without binding transmitter and in the absence of neuronal activity.
\end{abstract}

To function appropriately, motoneurons must form highly specific synaptic connections with skeletal muscles. To make these connections, developing motoneurons and muscle cells interact to coordinate the organization of presynaptic and postsynaptic elements of neuromuscular junctions and to place neuronal terminals on appropriate muscle fibers. Although much is known about the development of the structure of neuromuscular junctions and the formation of specific neuromuscular connections, little is understood about the cellular interactions that regulate these processes.

To form functional synapses, synaptic specializations are elaborated (Jacob and Lentz, 1979) and maintained (BaliceGordon and Lichtman, 1990; Chen et al., 1991) in close apposition by presynaptic and postsynaptic cells. Cell culture studies in avian, amphibian, and mammalian species have shown that muscle cells express and cluster $\mathrm{ACh}$ receptors (AChRs) in the absence of neurons (Steinbach and Bloch, 1986, and references therein), and that nerve contact elicits a redistribution of

Received Oct. 3, 1991; revised Dec. 9, 1991; accepted Dec. 18, 1991

We thank Reida Kimmel and Sean Posten for photographic assistance, Sue Pike and Judith Eisen for use of the laser, and Charles Kimmel and Janis Weeks for critical comments on the manuscript. The work was supported by National Institutes of Health Grants NS21132, HD22486, and GM7257, and an R.C.D.A to M.W.

Correspondence should be addressed to Monte Westerfield at the above address.

Present address: Department of Genetics SK-50, J205 Biochemistry \& Genetics Building, University of Washington, Seattle, WA 98195.

Copyright (c) 1992 Society for Neuroscience $0270-6474 / 92 / 121859-08 \$ 05.00 / 0$ muscle receptor clusters so that they become preferentially associated with growth cones and neurites (Anderson and Cohen, 1977; Frank and Fischbach, 1979). The redistribution includes the dispersal of existing clusters, the lateral migration of existing receptors, and the insertion of new receptors directly into the regions of nerve contact (Peng and Poo, 1986). These in vitro studies have led to the popularly held view that neuronal branches and growth cones play an important role in determining the distribution of AChRs but that muscle cells also follow an autonomous program of receptor clustering. Recent studies in chicks, however, have challenged this view, because very few AChR clusters form on muscle cells in the absence of innervation in vivo (Philips et al., 1985; Fallon and Gelfman, 1989; Dahm and Landmesser, 1991). Thus, it is still unclear to what extent muscle cells depend upon the motor nerves to form and organize their postsynaptic specializations.

We studied the earliest interactions between individual identified motor growth cones and muscle cells in zebrafish embryos and between the same cells in culture to learn if nerves are required for the clustering of muscle AChRs. We used vital dyes to label the presynaptic and postsynaptic elements and thus were able to study the first contacts between cells, as well as the subsequent formation of neuromuscular junctions in living embryos. Upon initial contact between the growth cone and a musclc ccll, but not before, AChRs clustered at the point of contact, and the muscle began to produce transmitter-dependent twitches. Receptors clustered in a normal pattern in the absence of neuronal activity and when they were occupied by receptor blockers. However, in contrast to our own and previous in vitro studies, muscle fibers in live embryos deprived of nerve contact failed to cluster AChRs. We suggest that extrinsic factors, normally provided by the motor growth cone, direct the formation of postsynaptic specializations and that neuromuscular connections are specified by activity-independent interactions between presynaptic and postsynaptic cells.

\section{Materials and Methods}

Animals. Zebrafish embryos from the Oregon AB line were maintained at $28.5^{\circ} \mathrm{C}$ on a $14 \mathrm{hr}$ light $/ 10 \mathrm{hr}$ dark cycle. Embryos were reared and staged with standard methods (Westerfield, 1989). All embryo ages are reported as hours postfertilization (h). During experimental procedures, embryos older than $17 \mathrm{~h}$ were anesthetized in a $0.02 \%$ solution (Westerfield, 1989) of tricaine methanesulfonate (Sigma). Effective anesthesia completely paralyzed embryonic movements while heartbeat remained strong. Embryos recovered rapidly from this anesthesia and resumed normal body movements within seconds after being transferred to a normal medium.

Microscopy. Embryos were anesthetized and mounted between glass coverslips spaced $200 \mu \mathrm{m}$ apart, and viewed with a $40 \times$ water immersion lens with an additional magnification of 1.25-2.0x. The fluorescent signal from epillumination was filtered with rhodamine or fluorescein 


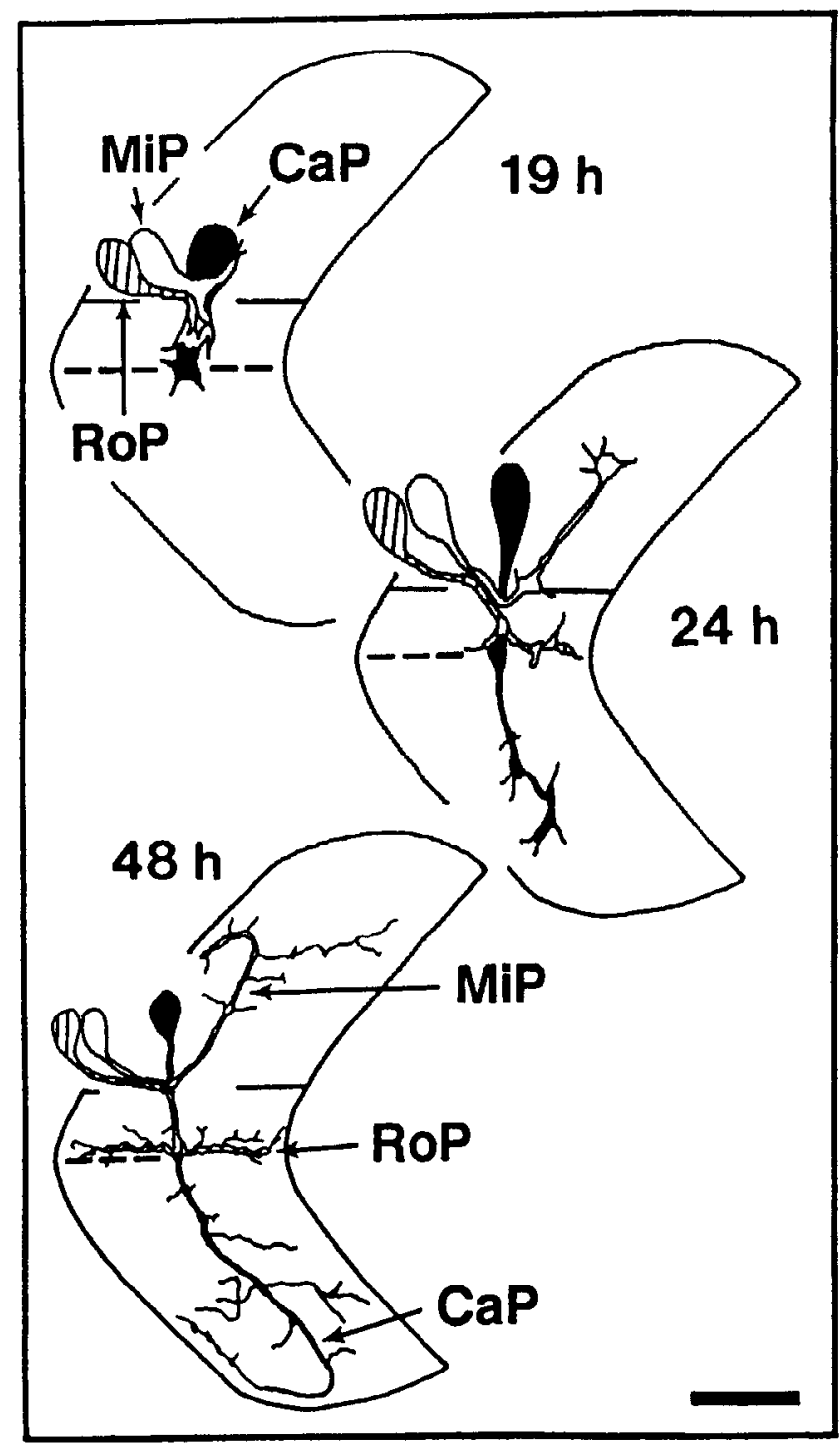

Figure 1. The growth cones of identified zebrafish motoneurons follow cell-specific pathways. This schematic diagram illustrates the cell body positions and the axonal trajectories of the three primary motoneurons, RoP (rostral primary, hatched), MiP (middle primary, white), and $C a P$ (caudal primary, black), as they appear in a single segment at three times, $19 \mathrm{~h}, 24 \mathrm{~h}$, and $48 \mathrm{~h}$. The solid horizontal line represents the ventral edge of the spinal cord and the broken horizontal line represents the location of the nascent horizontal septum and the MPs. The growth cones initially extend to the region of the nascent horizontal septum (19 $\mathrm{h}$ ) and then along the medial surface of the middle of the myotome ( 24 h). By the second day $(48 \mathrm{~h})$, branches extend throughout the muscle. Rostral is to the left and dorsal to the top in this and the following figures. Scale bar: $18 \mu \mathrm{m}$ at $19 \mathrm{~h}, 20 \mu \mathrm{m}$ at $24 \mathrm{~h}$, and $30 \mu \mathrm{m}$ at $48 \mathrm{~h}$.

filter sets and amplified with a silicon intensified target (SIT) camera (General Electric). Video images were digitized with an image processor (International Imaging Systems) controlled by a VAX 11/750 computer (Digital Equipment Corp.) and stored digitally and on analog videotape. Between observations, embryos were returned to medium without anesthetic.

Motoneuron labeling. The lipid soluble carbocyanine dye $\mathrm{DiO}\left(3,3^{\prime}-\right.$ dioctadecyloxacarbocyanine perchlorate; Molecular Probes) was used to label individual $\mathrm{CaP}$ motoneurons by extracellular application according to Liu and Westerfield (1990). Briefly, micropipettes with tip diameters of approximately $2.5 \mu \mathrm{m}$ were filled with a $1 \%$ solution of dye in dimethylformamide. The pipettes were inserted into the spinal cord and placed near the motoneuron's soma. A small bolus of dye was then pressure ejected onto the identified neuron.
$A C h R$ labeling. AChRs were labeled fluorescently in live embryos as previously described in Liu and Westerfield (1990). We used rhodamine conjugated $\alpha$-bungarotoxin (R-BTX), which binds to the $\alpha$-subunit of the AChR (Chang and Lee, 1963), to label receptors in the muscles of living embryos between the ages of 17 and $65 \mathrm{~h}$. Embryos were soaked in a mixture of $10^{-6} \mathrm{M}$ tetramethylrhodamine- $\alpha$-bungarotoxin (Molecular Probes) and 15\% dimethyl sulfoxide in embryo medium for 30-60 min at $7-10^{\circ} \mathrm{C}$. After treatment, the embryos were transferred to cold embryo medium and were slowly warmed back to $28.5^{\circ} \mathrm{C}$. Most embryos were retreated with toxin several times and the distributions of labeled receptor clusters were observed for several days.

We determined which aspects of the staining in the myotome were specific for clusters of AChRs by treating embryos with unlabeled toxin $\left(10^{-6} \mathrm{M}\right)$, followed by rhodamine-conjugated toxin. Because $\alpha$-bungarotoxin (BTX) binds to nicotinic AChRs with very high affinity, pretreatment with unlabeled toxin was expected to block all the specific binding sites and fluorescence detected after subsequent treatment with labeled toxin could be attributed to nonspecific staining. Faint homogeneous staining in the middle of the myotome and brighter staining at the segment borders were observed. No apparent clustering of R-BTX was observed after pretreatment with BTX, even with the SIT camera running at very high gain. These results suggested that only low levels of background labeling with rhodamine toxin are apparent. In general, specific labeling was punctate and brighter than the diffuse nonspecific labeling.

Motoneuron ablations. Individually identified motoneurons were killed with a laser as previously described (Eisen et al., 1989). The cell bodies of motoneurons were visualized in the spinal cord with differential interference contrast optics. Primary motoneurons were identified by the unique positions of their somata in the spinal cord at 16-18 h, prior to axogenesis, and were killed with pulsed irradiation by focusing a laser microbeam on their nuclei. Neurons were irradiated several times to ensure complete destruction. The somata of irradiated cells acquired a granular appearance and began to swell, and completely broke apart within about $10 \mathrm{~min}$. We verified the success of the ablations later with differential interference contrast optics.

Spinal ablations. Embryos (15-17 h) were mounted in agarose as previously described (Liu and Westerfield, 1990). With the aid of a dissecting microscope, a micropipette with a broken tip was inserted through the skin and into the spinal cord by hand. Suction was applied to the pipette and cells were removed from the spinal cord as the pipette tip was moved through one to three segments of the spinal cord. After recovering from the anesthesia, these animals behaved and appeared normal except for the missing spinal cord in the ablated segments. Some embryos were fixed and stained as whole-mounts with the zn-1 monoclonal antibody, which labels zebrafish motoneurons (Myers et al., 1986). The zn- 1 staining allowed us to confirm that we had removed all of the motoneurons.

Muscle culture. Neuronal and muscle cell cultures were established from $15-19 \mathrm{~h}$ zebrafish embryos. Embryos, in their chorions, were soaked in a $0.07 \%$ solution of bleach for 5-10 min. They were then rinsed in sterile medium, transferred to tissue culture dishes, and removed from their chorions with sterile forceps. About 100 embryos were incubated in $5 \mathrm{ml}$ of Custom ATV Solution (Irvine), which contains trypsin and no calcium, for $10 \mathrm{~min}$ at $28.5^{\circ} \mathrm{C}$. Following incubation, the embryos were dissociated by trituration through a Pasteur pipette. The dissociated cells were centrifuged for $3 \mathrm{~min}$ at $500 \mathrm{rpm}$ and resuspended in L15 tissue culture medium with glutamine and Fungibac (GIBCO), 3\% fetal calf serum, and an extract made from $7 \mathrm{~d}$ zebrafish. Drops of the cell suspension were plated onto glass coverslips and incubated at $28.5^{\circ} \mathrm{C}$.

\section{Results}

\section{Development of AChR cluster distribution}

We studied the earliest interactions between motor growth cones and muscle cells in zebrafish embryos to learn if nerves are required for the clustering of muscle AChRs in vivo. We first examined myotomal muscle cells in early zebrafish embryos to see when they expressed AChRs on their surfaces. We determined the onset and distribution of clusters of AChRs by labeling the receptors with R-BTX in living embryos as done previously in older embryos (Westerfield et al., 1990).

Clusters of AChRs appeared in a stereotyped sequence of 

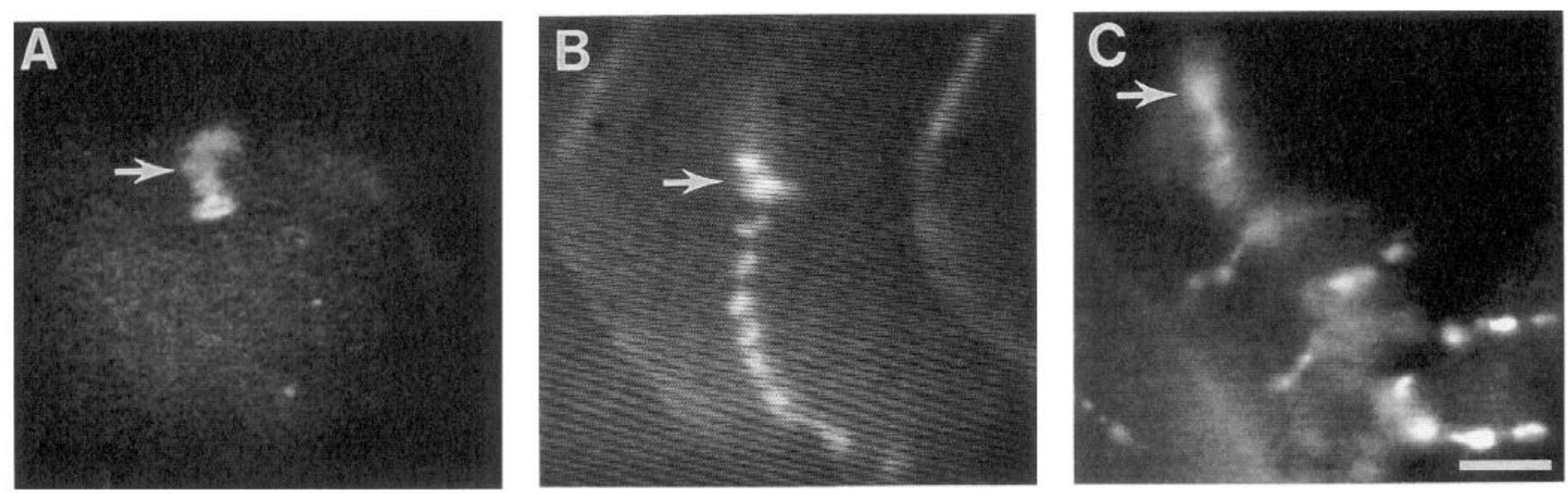

Figure 2. The addition of new AChR clusters follows the pattern of primary motoneuron axonal branching. Repeated views of R-BTX staining in the ventral regions of a single myotome are shown as they appeared at $20 \mathrm{~h}(A), 23 \mathrm{~h}(B)$, and $38 \mathrm{~h}(C)$. The earliest receptor clusters appeared in the ventral regions of a single myotome are shown as the As development proceeded, dense clusters of receptors formed along the medial surface near the nascent horizontal septum on the MPs $(A$, arrow). As development proceeded, dense clusters of receptors formed times, after the CaP axon had formed branches in the ventral myotome, receptor clusters were present throughout the myotome, and the clusters at the horizontal septum ( $C$, arrow) had condensed. The view in $C$ has been shifted ventrally. Segment 10 on left side. Scale bar, $10 \mu \mathrm{m}$.

positions within the myotome. We viewed the changing distribution of receptor clusters at several consecutive stages in development (Fig. 1) by repeated application of toxin. At early embryonic times (14-16 h) before growth cones entered the myotome, we observed no specific staining with R-BTX (6 embryos at $14 \mathrm{~h}, 5$ embryos at $15 \mathrm{~h}$, and 11 embryos at $16 \mathrm{~h}$ ). The earliest time that we detected AChRs was at $16-17 \mathrm{~h}$, just when the first growth cone of the pioneer $\mathrm{CaP}$ motoneuron began to leave the spinal cord. These earliest clusters were faint and in the region of the nascent horizontal septum on the surfaces of identified muscle cells, the muscle pioneers (MPs) where the $\mathrm{CaP}$ growth cone pauses before extending into the ventral myotome (Myers et al., 1986; Felsenfeld, 1988; Liu and Westerfield, 1990). The clusters appeared coincidently with the first twitches. Within 1-2 hr, these clusters grew bigger and brighter and became longitudinally oriented along the MPs (Fig. $2 A$ ). By $23 \mathrm{~h}$, a string of clusters extended along the pathways of the primary motoneurons in the middle of the myotome to its dorsal and ventral aspects (Fig. $2 B$ ). After the first $24 \mathrm{hr}$ of development, new clusters formed throughout the myotome, while the clusters in the region of the horizontal septum often condensed (Fig. $2 C$ ). The expanded distribution of receptor clusters was neither homogeneous nor haphazard but followed the known pattern of development of the first axonal arbors of the primary motoneurons (Liu and Westerfield, 1988, 1990), initially on the medial surface of the myotome and then throughout the muscle.

\section{Codistribution of receptor clusters and neuronal branches}

To see if the earliest receptor clusters formed where the branches of motoneurons contacted the muscle fibers, we concurrently labeled the pioneer motoneuron, CaP (Eisen et al., 1986), and AChRs (Westerfield et al., 1990). The main growth cone of labeled $\mathrm{CaP}$ motoneurons $(n=8)$ initially extended along the middle of the medial surface of the ventral myotome and formed an axon dotted with prominent varicosities as previously described (Liu and Westerfield, 1990). From the earliest times (16 h), labeled receptor clusters were distributed along this same pathway and were always associated with the $\mathrm{CaP}$ axon. Furthermore, the receptor clusters were usually $(88 \%$ of 168 varicosities) colocalized with the axonal varicosities. Later, side branches extended from some of these varicosities, and $\mathrm{AChR}$ clusters formed along these branches, usually in association with their varicosities (Fig. 3).

During the first $2 \mathrm{~d}$ of development, all receptor clusters in the ventral portion of the myotome were associated with labeled $\mathrm{CaP}$ axonal branches and varicosities (five CaPs in five embryos) and almost all branches and varicosities $(97 \%$ of 279 branches and 401 varicosities) had associated receptor clusters. Later observations of the few branches that lacked clusters showed that they too eventually had associated clusters (Fig. $3 C, D$ ). All receptor clusters in this region were stable throughout the $5 \mathrm{~d}$ period of our observations, with the exception of the clusters at the $\mathrm{CaP}$ branches near the horizontal septum, which disappeared as previously described even though those muscle fibers were contacted by other motoneurons (Liu and Westerfield, 1990). The latent period between neuronal contact and the clustering of muscle AChRs can be very short; the minimum interval is unknown, but it must be within minutes, because clusters sometimes appeared at the same time that the $\mathrm{CaP}$ growth cone arrived and because many newly sprouted side branches were associated with receptor clusters when they first appeared (Fig. $3 G, H)$. We saw no evidence of clusters forming before the growth cone arrived.

In the dorsal myotome and in portions of the ventral myotome near the horizontal septum, clusters of AChRs formed in the absence of labeled $\mathrm{CaP}$ axonal branches and were presumably associated with the branches of the other, unlabeled primary motoneurons. To examine this idea, we concurrently labeled the MiP or RoP motoneuron and AChRs (two MiPs, and two RoPs; Fig. 4) and found that their axonal branches, too, were associated with receptor clusters as seen for the $\mathrm{CaP}$ motoneuron. Moreover, all the clusters within the RoP or MiP territories were associated with branches of the labeled motoneuron.

\section{The role of motoneuronal branches in the clustering of AChRs}

These observations suggested that receptor clusters are localized exclusively in the vicinity of nerve branches, and that prior to nerve contact there are no apparent receptor clusters. This developmental sequence is consistent with the view that receptors 


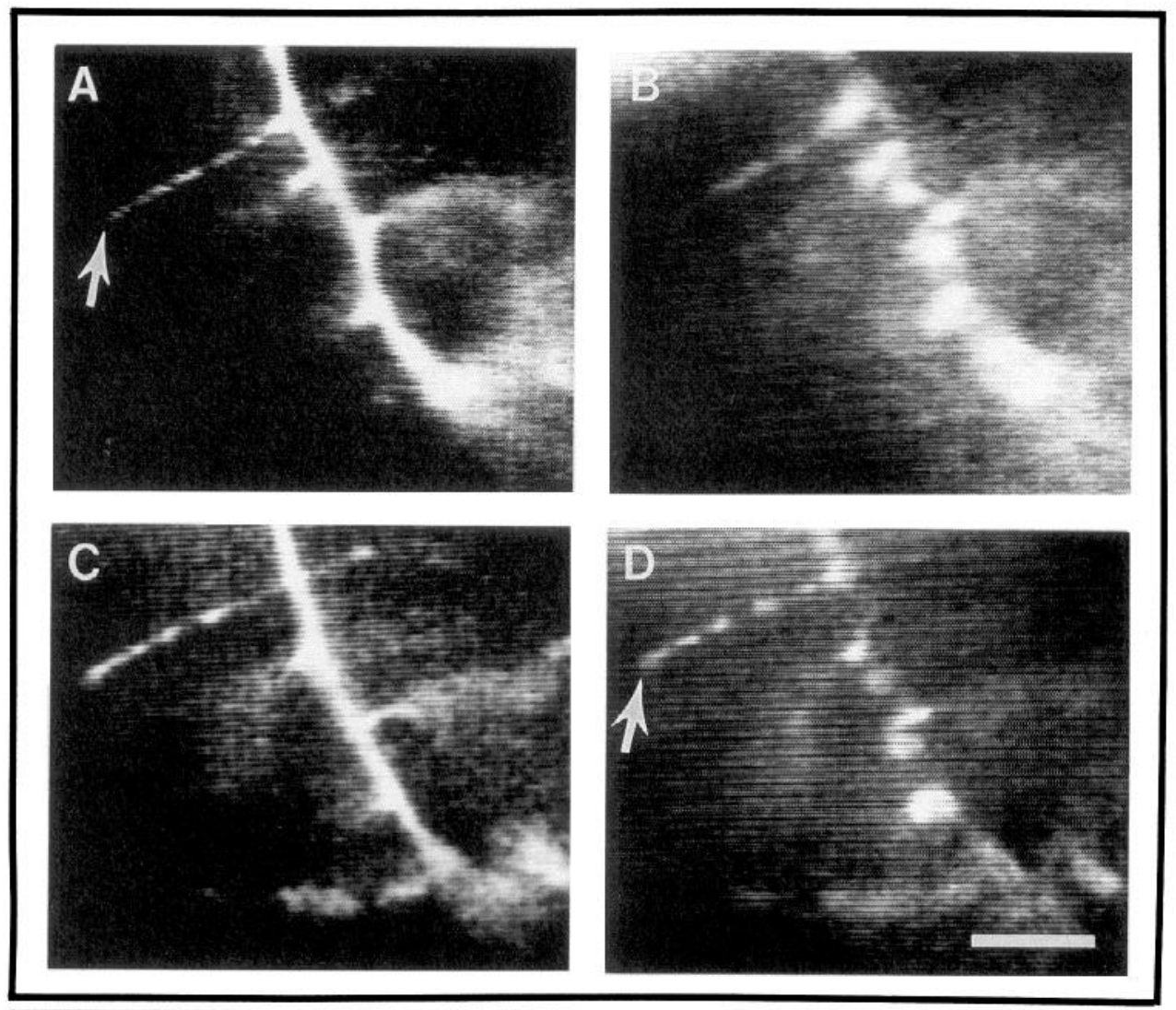

Figure 3. CaP neuronal branches and AChR clusters are colocalized. Top, Nerve contact can precede $\mathrm{AChR}$ formation. DiO-labeled CaP branches $(A$ and $C$ ) and associated receptor clusters $(B$ and $D)$ are shown as they appeared at $48 \mathrm{hr}(A$ and $B)$ and $51 \mathrm{hr}(C$ and $D)$. At $48 \mathrm{hr}$, the distal portion of an axonal branch $(A$, arrow) lacked associated receptor clusters $(B)$. However, $3 \mathrm{hr}$ later the branch $(C)$ was associated with receptor clusters all the way to its distal tip $(D$, arrow). Segment 10 on right side. Bottom, The latent period between neuronal contact and cluster formation is very short. A CaP neuronal branch (arrowheads in $E$ and $G$ ) and associated receptor clusters $(F$ and $H$ ) were observed at $48 \mathrm{hr}(E$ and $F)$ and again at $51 \mathrm{hr}(G$ and $H)$. During the $3 \mathrm{hr}$ period between observations, a small sidebranch extended ( $G$, arrow) and was already associated with a receptor cluster ( $H$, arrow). Segment 10 on right side. Scale bars, $10 \mu \mathrm{m}$.
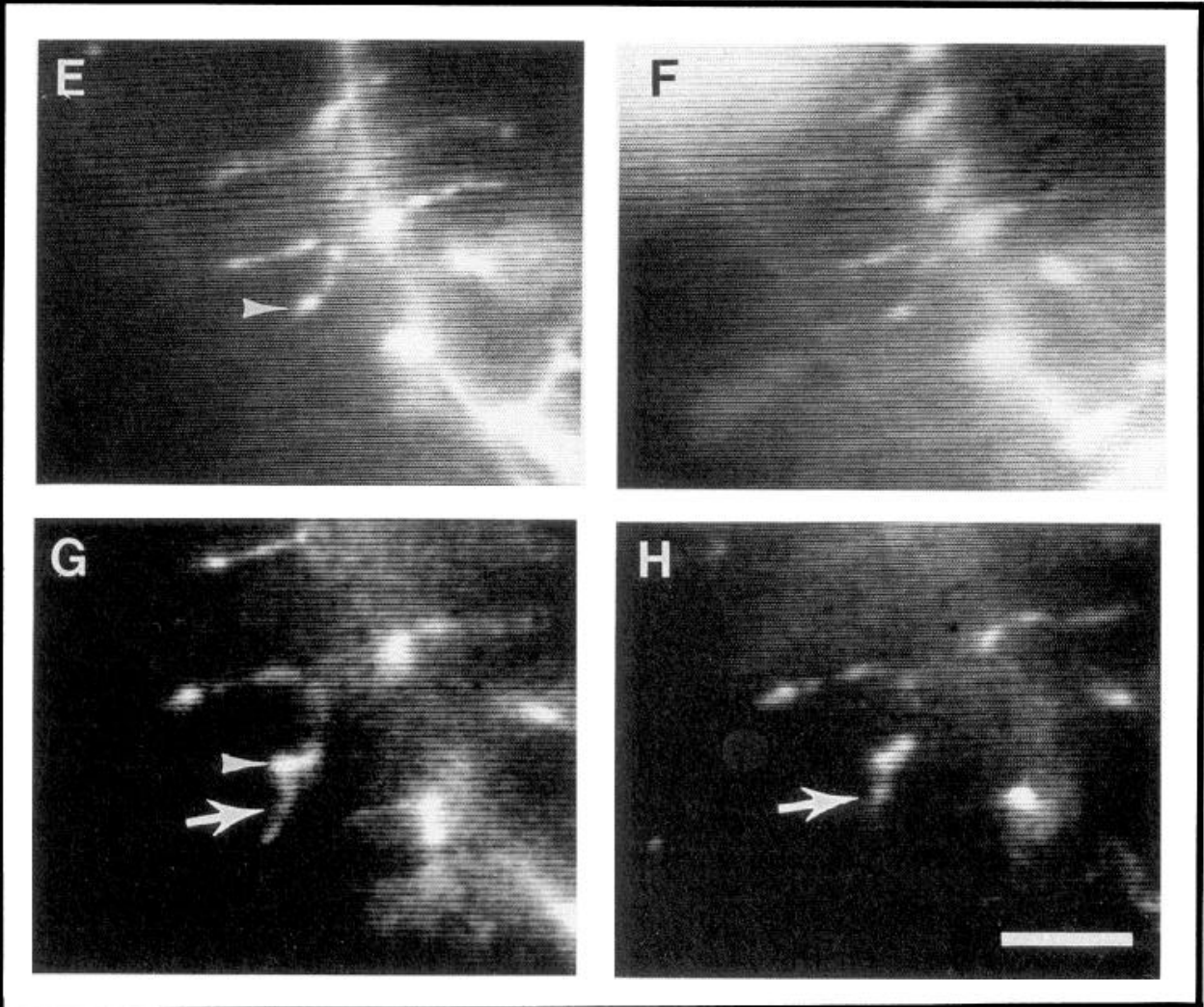

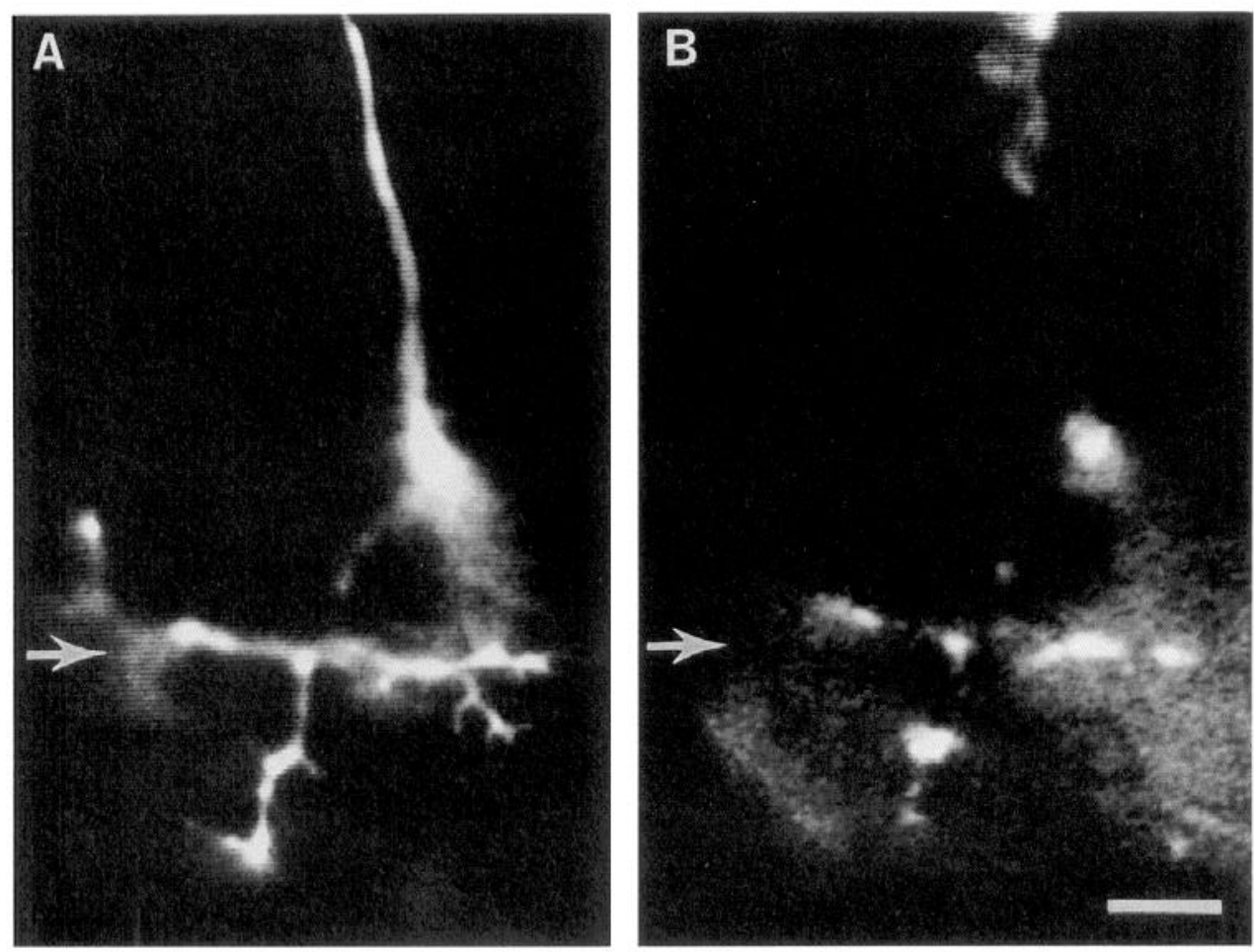

Figure 4. RoP branches are associated with AChR clusters. Concurrent labeling of an RoP motoneuron $(A)$ and AChRs $(B)$ showed that RoP branches were associated with receptor clusters as found for CaP branches. The arrow in cach photo points to the location of the horizontal septum. Segment 13 on right side; 43 h embryo. Scale bar, 10 $\mu \mathrm{m}$.

are induced to cluster at points of nerve contact (Steinbach and Bloch, 1986, and references therein). To test this idea critically, we examined the distribution of receptor clusters in myotomes in which we had killed individual motoneurons prior to axogenesis.

The clustering of AChRs within the specific territory of the CaP motoneuron was delayed and occurred abnormally in the absence of the $\mathrm{CaP}$ motoneuron. When we ablated only the $\mathrm{CaP}$ motoneuron prior to axogenesis, clusters of receptors failed to form in the normal CaP territory (all $23 \mathrm{CaPs}$ in 11 animals; Fig. 5) even after $30 \mathrm{~h}$. Starting around $36 \mathrm{~h}$, a time after which secondary motoneurons normally extend axons into the ventral muscle, receptor clusters began to appear, although the pattern was aberrant; the receptor clusters were smaller, fewer in number, fainter, and not necessarily located where the branches of the nerve normally form (data not shown). However, in all the segments in which the $\mathrm{CaP}$ motoneuron was ablated, the pattern of receptor clusters developed normally in the dorsal myotome and at the horizontal septum, on the MPs, regions that are innervated by other motoneurons.

The aberrant receptor clusters that eventually appeared in the regions devoid of $\mathrm{CaP}$ branches could have been formed autonomously by the muscles, or they could have been induced by the ingrowth of secondary motoneurons that were unaffected by the ablation and that normally innervate the ventral myotome later than the CaP motoneuron (Myers et al., 1986).

To distinguish between these possibilities, we examined the pattern of AChR clusters in myotomes deprived of all innervation. We removed one or more segments of spinal cord from nine embryos at about $16 \mathrm{~h}$, prior to outgrowth of the first motor growth cones from the cord (Eisen et al., 1986). At $24 \mathrm{~h}$, two of the nine embryos had a few remaining neurons in the ablated segments, presumably due to incomplete removal of the spinal cord. Clusters of AChRs formed in the myotomes associated with these segments. The seven other embryos completely lacked receptor clusters in the ablated segments (Fig. 6). By $65 \mathrm{~h}$, five of the remaining seven embryos formed some abnormal receptor clusters; these clusters were sparse and many muscle fibers lacked clusters completely, as would be expected in a region contacted by relatively few axonal branches. These branches

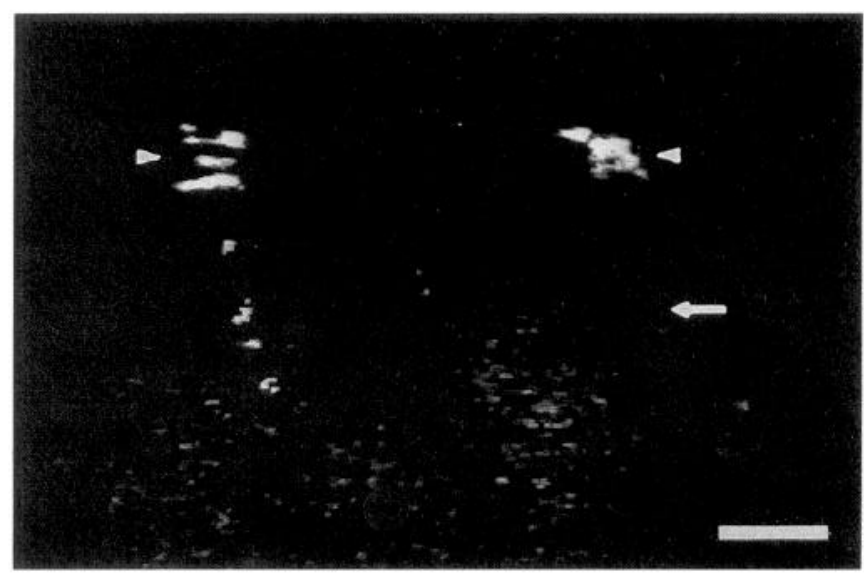

Figure 5. Killing the CaP motoneuron with a laser microbeam disrupts the pattern of AChR clusters. Receptor clusters in a normal segment (left) were distributed along the medial surface of the ventral myotome by $22 \mathrm{~h}$. In the adjacent segment (right) of the same fish, the CaP motoneuron was killed by laser irradiation at $14 \mathrm{~h}$, prior to axogenesis. At $22 \mathrm{~h}$, this segment lacked receptor clusters along the CaP pathway (arrow) but had developed clusters at the nascent horizontal septum (arrowheads) where the paths of the remaining motoneurons converge (Eisen et al., 1986). In the segments in which the CaP motoneuron was ablated, the pattern of receptor clusters developed normally in the dorsal myotome (data not shown), a region that is innervated by other motoneurons. Segments 8 (left) and 9 (right) on right side. Scale bar, 10 $\mu \mathrm{m}$. 
Figure 6. Aneural myotomes lack AChR clusters. Slightly more than one spinal segment was removed from the embryo prior to axogenesis using a fine micropipette, resulting in an aneural myotome. R-BTX labeling showed that the uninnervated myotome contained no apparent receptor clusters (arrow), although neighboring myotomes did (arrowheads). The bright signal in the ventral part of the aneural segment is caused by the birefringence of the muscle cells and is not due to R-BTX labeling. The aneural segment is 11 on left side. Scale bar, $15 \mu \mathrm{m}$.

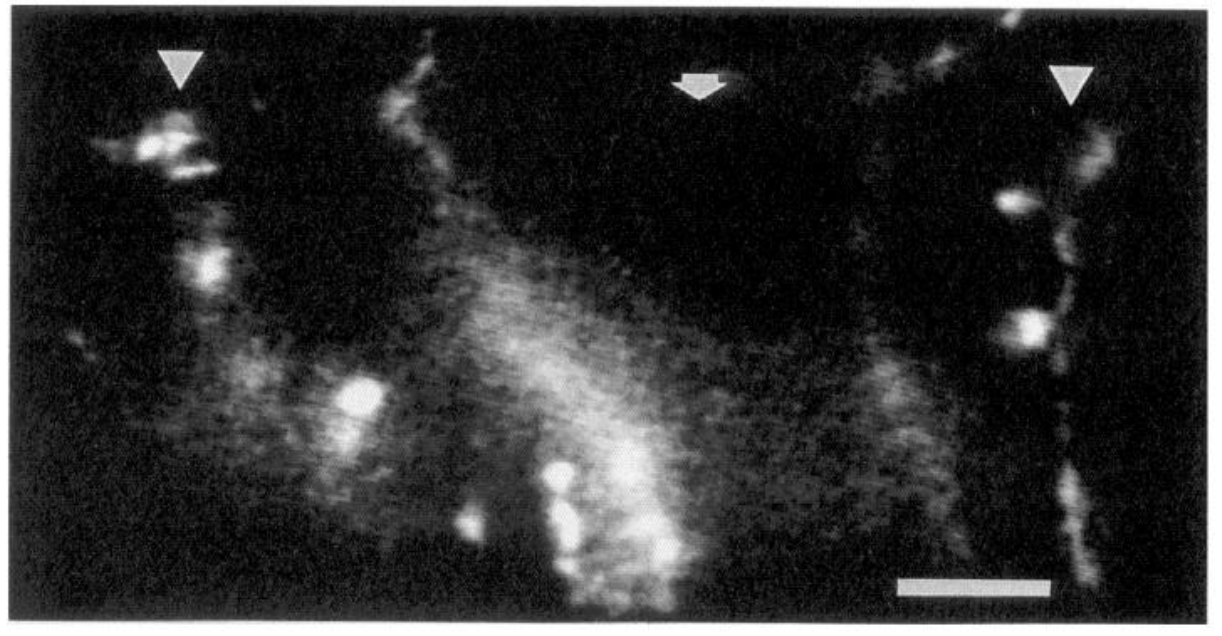

may have arisen from adjacent, intact spinal segments (Westerfield et al., 1986) or from a few surviving motoneurons in the ablated segments. No receptor clusters appeared within the affected myotomes in the remaining two embryos, even after $72 \mathrm{~h}$, suggesting that they completely lacked AChR clusters.

\section{The influence of neuromuscular transmission on receptor clustering}

These observations, in contrast to older studies (Braithwait and Harris, 1979; Harris, 1981; Creazzo and Sohal, 1983) but in agreement with more recent observations (Philips et al., 1985; Fallon and Gelfman, 1989; Dahm and Landmesser, 1991), demonstrated that clustering of AChRs by the muscle is drastically reduced when the motoneurons are absent. Thus, clustering may require neuromuscular transmission. We tested this idea by blocking synaptic transmission with chronic treatments of tricaine or BTX from before axonal outgrowth until several days of development (Liu and Westerfield, 1990). We ascertained the effectiveness of neuromuscular blockade by observing no movements, or spontaneous or evoked end-plate potentials in the muscle (Grunwald et al., 1988). Receptors were labeled with R-BTX, and the pattern of clusters was recorded. Consistent with previous in vitro (Anderson and Cohen, 1977; Davey and
Cohen, 1986) and in vivo observations (Dahm and Landmesser, 1991), receptor clusters formed in the presence of activity blockers. Additionally, the distribution of receptor clusters in these paralyzed embryos appeared at the normal time and in a normal pattern (three animals in tricaine, five in BTX), demonstrating that AChRs cluster normally upon neuronal contact even in the absence of neuromuscular transmission.

\section{Distribution of receptor clusters on cultured zebrafish muscles}

Previous studies of cell cultures have demonstrated that muscle fibers cluster AChRs in the absence of nerve contact (Steinbach and Bloch, 1986), although neuronal contact elicits a redistribution of receptor clusters (Peng and Poo, 1986). This is in contrast to our observations in live zebrafish embryos, where receptor clusters failed to form in the absence of innervation (Figs. 5, 6). This difference might be due to muscle properties unique to fish or to differences in the way muscle cells differentiate in cell culture and in vivo. For a more direct comparison, we cultured dissociated zebrafish muscle cells at low density before and after nerve contact and examined R-BTX labeling on isolated muscle fibers to see whether contact by nerve branches was necessary for cluster formation.

In both types of cultures, dissociated before or after the mus-
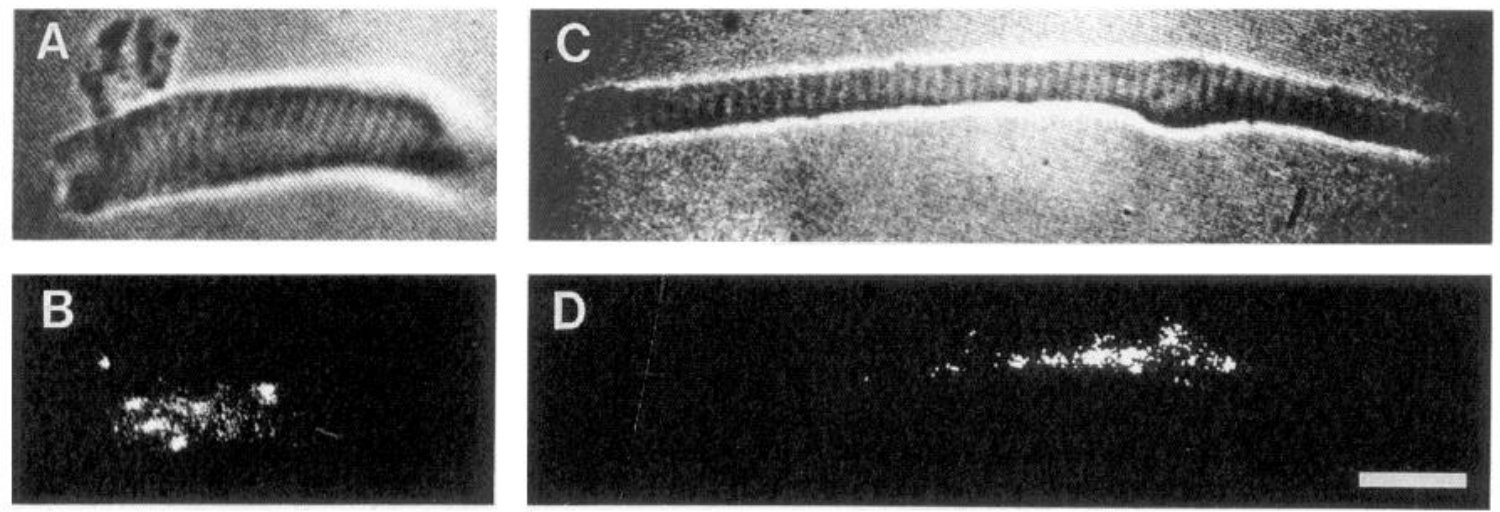

Figure 7. Uninnervated zebrafish muscle cells cluster AChRs in culture. Muscle cells $(A$ and $C)$, apparently uncontacted by other cells in the culture dish, developed clusters of $\operatorname{AChRs}(B$ and $D)$ by the second day in culture. The muscle cells were dissociated from embryos before ( 16 hr, $A$ and $B$ ) or after ( $19 \mathrm{~h}, C$ and $D)$ motoneurons had sprouted growth cones that could have contacted these cells. In both cases, isolated, striated cells with receptor clusters were found. Similar results were obtained in 40 wells from five platings before 24 wells from three platings after the muscles were innervated. Scale bar, $25 \mu \mathrm{m}$. 
cles were innervated, striated cells had easily observable clusters of AChRs on their surfaces (Fig. 7). In each case, some of the labeled striated cells were completely isolated from other cells and were apparently uninnervated. Thus, cultured zcbrafish muscle cells cluster AChRs, as do muscles from other vertebrates. Furthermore, the size and brightness of the clusters suggested that we probably would not have missed small or faint clusters that might have formed in vivo without innervation.

\section{Discussion}

\section{Neuronal induction of $A C h R$ clusters}

Nerve contact has been shown to have important influences on muscle development (Slater, 1982; Steinbach and Bloch, 1986; Van Essen et al., 1990), although many aspects of muscle differentiation occur independently (Crow and Stockdale, 1986; Sanes, 1987). The results of our experiments in which muscles were deprived of innervation suggest that muscle fibers in the intact embryo depend on influences from the nerve to instruct the placement and distribution of AChRs. If motoneurons were ablatcd beforc thcy sprouted growth cones, receptor clusters failed to form on the aneural muscles (Figs. 5, 6).

The instructions that muscles receive from motoneurons in zebrafish embryos are very precise and local in nature; receptor clusters form only at sites of neuronal contact, consistent with studies in other in vivo systems (Van Essen, 1982). In a recent study in chick, however, Dahm and Landmesser (1991) observed AChR clusters in limb muscles 100-200 $\mu \mathrm{m}$ from the nerve trunk before muscle nerve branches had formed. Our observations, in contrast, demonstrated that clusters always formed precisely within a few micrometers of the main body of the growth cone. The explanation for the different results obtained in these two studies is unclear. One difference is that development in the zebrafish is much faster; there may not have been enough time for ectopic clusters to form before the growth cone contacted the muscle fibers. This seems unlikely, however, because even at later times, we ncver saw clusters form away from the point of contact. Another difference is the number of axons present in the two systems; maybe the hundreds of chick growth cones, in contrast to the single zebrafish growth cone, produce enough signal to induce clustering at a distance.

Continued nerve contact, apparently, is important for the maintenance of receptor clusters; when neuronal branches retract, the AChR clusters associated with them also selectively disappear (Liu and Westerfield, 1990). Thus, neuronal contact determines the pattern of AChR distribution and, at least initially, is also important for the maintenance of receptor clusters in the embryo. In chicks (Jacob and Lentz, 1979; Meiniel and Bourgeois, 1982) and mammals (Frank et al., 1975; Steinbach, 1981; Slater, 1982), receptor clusters eventually become much more stable and independent of the presence of the nerve terminal as neuromuscular junctions mature (Wigston, 1990).

Muscle fibers in zcbrafish embryos are devoid of AChR clusters prior to nerve contact, and clusters fail to form when the muscle is denied innervation. Similarly, aneural chick muscles produce very few receptor clusters (Philips et al., 1985; Fallon and Gelfman, 1989; Dahm and Landmesser, 1991). In contrast, previous studies in embryonic rats (Braithwaite and Harris, 1979; Harris, 1981) suggested that, in the absence of innervation due to treatment with $\beta$-bungarotoxin, which kills motoneurons, receptor clusters formed at sites where innervation normally occurs. There are several possible explanations for this discrepancy. For instance, the $\beta$-bungarotoxin treatment may have failed to kill the motoneurons before they formed axons that contacted the developing muscle cells. Contact with the muscles, no matter how brief, may have been enough to induce the formation of AChR clustcrs. Similarly, recent reports suggest that some motoneurons survive $\beta$-bungarotoxin treatment (Ross et al., 1987; Condon et al., 1990); the survivors could extend axons that induce the clustering of receptors.

\section{The clustering of AChRs on muscles grown in cell culture}

Zebrafish muscle cells, like those from other vertebrates (Steinbach and Bloch, 1986, and references therein), spontaneously cluster AChRs when grown alone in cell culture (Fig. 7). Previous culture studies have shown that nerve-induced receptor clusters are formed by the redistribution of preexisting receptor clusters and by localized insertion of new receptors (Anderson and Cohen, 1977; Frank and Fischbach, 1979; Peng and Poo, 1986; Steinbach and Bloch, 1986). On the other hand, muscle fibers in the intact zebrafish embryo (Figs. 5, 6) have no detectable clusters of $\mathrm{AChRs}$ prior to nerve contact and, like chick muscles (Philips ct al., 1985; Fallon and Gelfman, 1989; Dahm and Landmesser, 1991), cluster very few receptors spontaneously in the absence of innervation. One explanation for the disparity between previous in vivo and in vitro observations may be a difference in the types of myotubes used because cell culture experiments exclusively used secondary myotubes that form well after the period of initial synaptogenesis. However, our observations have eliminated this uncertainty because the same muscle cells were examined in vivo and in vitro. Our results thus raise the possibility that the clustering of AChRs, which occurs on isolated muscle cells in culture, is triggered by conditions in the culture or by the explant procedure and does not represent the normal course of muscle cell differentiation. We suggest that during normal development in vivo, motor axons exclusively induce the clustering of $\mathrm{AChRs}$ on skeletal muscle fibers.

\section{Mechanisms of induction}

Zebrafish muscles are cholinergically activated from the time that motor growth cones first extend into the muscles. Although it is tempting to speculate that transmitter-receptor interactions may modulate synaptic specificity in the zebrafish motor system, as suggested from work in invertebrates (Haydon et al., 1984; Goldberg and Kater, 1989), our results argue against this conclusion. Paralyzing doses of curare or tricaine, which block neuromuscular transmission, fail to impair the development of normal patterns of AChR clusters. Moreover, normal patterns of neuromuscular innervation are established in a zebrafish mutant that lacks functional AChRs (Westerfield et al., 1990).

On the other hand, there may be factors, in addition to $\mathrm{ACh}$, released by growth cones that affect the distribution of AChRs. Factors with $\mathrm{AChR}$ clustering activity have been extracted from electric fish (Nitkin et al., 1987), chick nervous system (Usdin and Fischbach, 1986), and pig brain (Salpeter ct al., 1982). Thesc factors would presumably act via contact between the growth cones and muscle fibers or by non-impulse-mediated release, because we found that receptors cluster in doses of tricaine that block action potentials.

There are a variety of mechanisms that might operate independently of ACh-mediated activity to specify neuromuscular connections. Various compunents of the substratum (Letourneau, 1982; Hunter et al., 1989) and cell-surface molecules in regions through which growth cones extend may influence the direction of axonal growth and the specificity of the synaptic 
connections they form. These influences could be mediated by specific cell-surface receptors expressed by growth cones (Tomaselli et al., 1986, 1988; Ruoslahti and Pierschbacher, 1987). Thus, a series of recognition events may guide motor growth cones to appropriate muscle regions where specific interactions between the growth cones and muscle fibers lead to differentiation of neuromuscular junctions. Our results suggest that, for pioneer motoneurons in the zebrafish, most if not all of these steps are activity independent.

\section{References}

Anderson MJ, Cohen MW (1977) Nerve-induced and spontaneous redistribution of acetylchuline receptors on cultured muscle cells. J Physiol 268: 757-773.

Balice-Gordon RJ, Lichtman JW (1990) In vivo visualization of the growth of pre- and postsynaptic elements of neuromuscular junctions in the mouse. J Neurosci 10:894-908.

Braithwaite AW, Harris AJ (1979) Neural influence on acetylcholine receptor clusters in embryonic development of skeletal muscles. Nature 279:549-551.

Chang CC, Lee CY (1963) Isolation of neurotoxins from the venom of Bungarus multicinctus and their modes of neuromuscular blocking action. Arch Int Pharmacodyn Ther 144:241-257.

Chen L, Folsom DB, Ko C-P (1991) The remodeling of synaptic extracellular matrix and its dynamic relationship with nerve terminals at living frog neuromuscular junctions. J Neurosci 11:2920-2930.

Condon K, Silberstein L, Blau HM, Thompson WJ (1990) Differentiation of fiber types in aneural musculature of the prenatal rat hindlimb. Dev Biol 138:275-295.

Creazzo TL, Sohal GS (1983) Neural control of embryonic acetylcholine receptors and skeletal muscle. Cell Tissue Res 228:1-12.

Crow MT, Stockdale FE (1986) Myosin expression and specialization among the earliest muscle fibers of the developing avian limb. Dev Biol 113:238-254.

Dahm LM, Landmesser LT (1991) The regulation of synaptogenesis during normal development and following activity blockade. J Neurosci 11:238-255.

Davcy DF, Cohen MW (1986) Localization of acetylcholine receptors and cholinesterase on nerve-contacted and noncontacted muscle cells grown in the presence of agents that block action potentials. J Neurosci 6:673-680.

Eisen JS, Myers PZ, Westerfield M (1986) Pathway selection by growth cones of identified motoneurons in live zebra fish embryos. Nature 320:269-271.

Eisen JS, Pike SH, Debu B (1989) The growth cones of identified motoneurons in embryonic zebrafish select appropriate pathways in the absence of specific cellular interactions. Neuron 2:1097-1 104.

Fallon JR, Gelfman CE (1989) Agrin-related molecules are concentrated at acetylcholine receptor clusters in normal and aneural developing muscle. J Cell Biol 108:1527-1535.

Felsenfeld AL (1988) Characterization of mutations affecting myofibrillogenesis in the zebrafish, Brachydanio rerio. $\mathrm{PhD}$ dissertation, University of Oregon.

Frank E, Fischbach G (1979) Early events in neuromuscular junction formation in vitro. J Cell Biol 83:143-158.

Frank E, Gautvik K, Sommerschild H (1975) Cholinergic receptors at denervated mammalian motor end-plates. Acta Physiol Scand 95: 66-76.

Goldberg JI, Kater SB (1989) Expression and function of the neurotransmitter serotonin during development of the helisoma nervous system. Dev Biol 131:483-495.

Grunwald DJ, Kimmel CB, Westerfield M, Walker C, Streisinger G (1988) A neural degeneration mutation that spares primary neurons in the zebrafish. Dev Biol 126:115-128.

Harris AJ (1981) Embryonic growth and innervation of rat skeletal muscles. III. Neural regulation of junctional and extra-junctional acetylcholine receptor clusters. Philos Trans R Soc Lond Biol 293:287314.

Haydon PG, McCobb DP, Kater SB (1984) Serotonin selectively inhibits growth cone motility and synaptogenesis of specific identified neurons. Science 226:561-564.

Hunter DD, Shah V, Merlie JP, Sanes JR (1989) A laminin-like ad- hesive protein concentrated in the synaptic cleft of the neuromuscular junction. Nature 338:229-234.

Jacob M, Lentz TL (1979) Localization of acetylcholine receptors by means of horseradish peroxidase- $\alpha$-bungarotoxin during formation and development of the neuromuscular junction in the chick embryo. J Cell Biol 82:195-211.

Letourneau PC (1982) Nerve fiber growth and its regulation by extrinsic factors. In: Neuronal development (Spitzer NC, ed), pp 213 254. New York: Plenum.

Liu DW, Westerfield M (1988) Function of identified motoneurons and co-ordination of primary and secondary motor systems during zebrafish swimming. J Physiol (Lond) 403:73-89.

Liu DW, Westerfield M (1990) The formation of terminal fields in the absence of competitive interactions among primary motoneurons in the zebrafish. J Neurosci 10:3947-3959.

Meiniel R, Bourgeois JP (1982) Appearance and distribution in situ of nicotinic acetylcholine receptors in cervical myotomes of young chick embryos. Anat Embryol 164:349-368.

Myers PZ, Eisen JS, Westerfield M (1986) Development and axonal outgrowth of identified motoneurons in the zebrafish. J Neurosci 6: 2278-2289

Nitkin RM, Smith MA, Magill C, Fallon JR, Yao Y-MM, Wallace BG, McMahan UJ (1987) Identification of agrin, a synaptic organizing protein from Torpedo electric organ. J Cell Biol 105:2471-2478.

Peng HB, Poo M (1986) Formation and dispersal of acetylcholine receptor cluster in muscle cells. Trends Neurosci 9:125-129.

Phillips WD, Lai K, Bennett MR (1985) Spatial distribution and size of acetylcholine receptor clusters determined by motor nerves in developing chick muscles. J Neurocytol 14:309-325.

Ross JJ, Duxson MJ, Harris AJ (1987) Neural determination of muscle fibre numbers in embryonic rat lumbrical muscles. Development 100: 395-409.

Ruoslahti E, Pierchbacher MD (1987) New perspectivies in cell adhesion: RGD and integrins. Science 238:491-497.

Salpeter MM, Spanton S, Holley K, Podleski TR (1982) Brain extract causes acetylcholine receptor redistribution which mimics some early events at developing neuromuscular junctions. J Cell Biol 93:417425.

Sanes JR (1987) Cell lineage and the origin of muscle fiber types. Trend Neurosci 10:219-220.

Slater CR (1982) Neural influence on the postnatal changes in acetylcholine receptor distribution at nerve-muscle junctions in the mouse. Dev Biol 94:23-30.

Steinbach JH (1981) Developmental changes in acetylcholine receptor aggregates at rat skeletal neuromuscular junctions. Dev Biol 84:267276 .

Steinbach JH, Bloch RJ (1986) The distribution of acetylcholine receptors on vertebrate skeletal muscle cells. In: Receptors in cellular recognition and developmental processes. New York: Academic.

Tomaselli KJ, Reichardt LF, Bixby JL (1986) Distinct molecular interactions mediate neuronal process outgrowth on non-neuronal cell surfaces and extracellular matrices. J Cell Biol 103:2659-2672.

Tomaselli KJ, Neugebauer KN, Bixby JL, Lilien J, Reichardt LF (1988) $\mathrm{N}$-cadherin and integrins: two receptor systems that mediate neuronal process outgrowth on astrocyte surfaces. Neuron 1:33-43.

Usdin T, Fischbach GD (1986) Purification and characterization of a polypeptide from chick brain that promotes the accumulation of acetylcholine receptors in chick myotubes. J Cell Biol 103:493-507.

Van Essen DC (1982) Neuromuscular synapse elimination: structural, functional, and mechanistic aspects. In: Neuronal development (Spitzer NC, ed). New York: Plenum.

Van Essen DC, Gordon H, Soha JM, Fraser SE (1990) Synaptic dynamics at the neuromuscular junction: mechanisms and models. $J$ Neurobiol 21:223-249.

Westerfield M (1989) The zebrafish book. Eugene, OR: University of Oregon.

Westerfield M, McMurray JV, Eisen JS (1986) Identified motoneurons and their innervation of axial muscles in the zebrafish. J Neurosci 6: $2267-2277$.

Westerfield M, Liu DW, Kimmel CB, Walker C (1990) Normal pathfinding by pioneer motor growth cones in mutant zebrafish lacking functional acetylcholine receptors. Neuron 3:867-874.

Wigston D (1990) Tug-of-war at the neuromuscular junction. Trends Neurosci 13:309-312. 